\title{
Highly specific reasons for nonadherence to antiretroviral therapy: results from the German adherence study
}

This article was published in the following Dove Press journal:

Patient Preference and Adherence

8 November 2017

Number of times this article has been viewed

\author{
Johanna Boretzki ${ }^{1,2}$ \\ Eva Wolf ${ }^{3}$ \\ Carmen Wiese ${ }^{4}$ \\ Sebastian $\mathrm{Noe}^{4}$ \\ Annamaria Balogh ${ }^{3}$ \\ Anja Meurer ${ }^{5}$ \\ Ivanka Krznaric 6 \\ Alexander Zink ${ }^{7}$ \\ Christian Lersch' \\ Christoph D Spinner ${ }^{1,2}$ \\ 'Department of Medicine II, University \\ Hospital Klinikum rechts der Isar, \\ Munich, ${ }^{2}$ German Center for Infection \\ Research, Partner Site Munich, ${ }^{3}$ MUC \\ Research, Munich, ${ }^{4}$ MVZ Karlsplatz, \\ HIV Clinical Care Center, Munich, \\ ${ }^{5}$ Center for Infectiology and Internal \\ Medicine, Munich, ${ }^{6}$ Center for \\ Infectiology Prenzlauer Berg, Berlin, \\ ${ }^{7}$ Department of Dermatology and \\ Allergology, University Hospital \\ Klinikum rechts der Isar, Munich, \\ Germany
}

Correspondence: Johanna Boretzki Department of Medicine II, University Hospital Klinikum rechts der Isar, Ismaninger Street 22, 81675 Munich, Germany Tel +4989 4l40 5236 Fax +4989 4I407555 Email johanna.boretzki@web.de
Background: Reasons for and frequency of nonadherence to antiretroviral therapy (ART) may have changed due to pharmacological improvements. In addition, the importance of known non-pharmacologic reasons for nonadherence is unclear.

Methods: We performed a cross-sectional, noninterventional, multicenter study to identify current reasons for nonadherence. Patients were categorized by physicians into the following adherence groups: good, unstable, or poor adherence. Co-variables of interest included age, sex, time since HIV diagnosis, ART duration, current ART regimen, HIV transmission route, comorbidity, HIV-1 RNA viral load (VL), and CD4 cell count. Patients self-reported the number of missed doses and provided their specific reasons for nonadherent behavior. Statistical analyses were performed using Fisher's extended exact test, Kruskal-Wallis test, and logistic regression models.

Results: Our study assessed 215 participants with good $(n=162)$, unstable $(n=36)$, and poor adherence $(n=17)$. Compared to patients with good adherence, patients with unstable and poor adherence reported more often to have missed at least one dose during the last week (good 11\% vs unstable $47 \%$ vs poor $63 \%, p<0.001$ ). Physicians' adherence assessment was concordant with patients' self-reports of missed doses during the last week (no vs one or more) in $81 \%$ cases. Similarly, we found a strong association of physicians' assessment with viral suppression. Logistic regression analysis showed that "reduced adherence" - defined as unstable or poor - was significantly associated with patients $<30$ years old, intravenous drug use, history of acquired immune deficiency syndrome (AIDS), and psychiatric disorders $(p<0.05)$. Univariate analyses showed that specific reasons, such as questioning the efficacy/dosing of ART, HIV stigma, interactive toxicity beliefs regarding alcohol and/or party drugs, and dissatisfaction with regimen complexity, correlated with unstable or poor adherence $(p<0.05)$.

Conclusion: Identification of factors associated with poor adherence helps in identifying patients with a higher risk for nonadherence. Reasons for nonadherence should be directly addressed in every patient, because they are common and constitute possible adherence intervention points.

Keywords: human immunodeficiency virus, HIV, antiretroviral therapy, ART, adherence, nonadherence, patients' beliefs

\section{Introduction}

The efficacy of antiretroviral therapy (ART) has improved significantly within the recent years and has subsequently led to normal life expectancy in human immunodeficiency virus (HIV)-positive patients. ${ }^{1-4}$ Adherence to ART is crucial to overall treatment success. ${ }^{5-9}$ Yet, evaluation of adherence remains challenging. In addition to medication 
event monitoring systems (MEMSs), self-reports of adherence have been studied. ${ }^{7,10-13}$ Adherence questionnaires have been evaluated for clinical use. ${ }^{14-16}$ These questionnaires offer the opportunity to assess adherence and, importantly, the reasons for adherence problems. Adherence is known to be a complex behavior influenced by many factors, such as sociocultural background, comorbidities, and HIV- and ARTrelated factors. ${ }^{17,18}$ Due to pharmacological improvements, drugs with lower dosing frequencies and side effects, as well as single-tablet regimens (STRs), have been developed and have rendered drug use less cumbersome for patients. ${ }^{6,19-21}$ Furthermore, the prevalence of nonadherence and the reasons for nonadherent behaviors may have changed over time, due to sociocultural progress. Therefore, it is unclear whether the results from earlier studies are applicable to the current treatment of patients.

To examine the complex influences of adherence currently, we analyzed the frequency of nonadherence, the patient-, HIV-, and ART-related factors associated with nonadherence, and patients' reasons for nonadherent behaviors in a large German HIV patient study group. To achieve a balanced distribution between adherent and non-adherent patients, disproportionately more participants with suspected adherence problems were subsequently included in the study group.

\section{Patients and methods Study design and patients}

The study was a qualitative and quantitative, cross-sectional, noninterventional, multicenter clinical trial. Physicians $(n=10)$ enrolled HIV-infected individuals aged 18 years and older, from September 2014 to April 2015 at four German centers (three primary care centers and one university hospital). Patients not receiving ART or those undergoing treatment for less than 6 months with still detectable viral loads (VLs) were excluded. Because of the expected low prevalence of nonadherence in Germany, recruitment of patients was not unselected; physicians were asked to enhance recruitment of patients with suspected nonadherence, thus ensuring a sufficient sample size of patients with adherence problems.

This study was officially approved by the ethics committee of the University Hospital Klinikum rechts der Isar of the Technical University of Munich, Germany (approval number 240/14). This study was performed according to the Declaration of Helsinki. The study objectives and protocol were explained by the study personnel to the patients. Written informed consent was obtained from all participants before including them in the study. This study was not registered because of the noninterventional and cross-sectional study design.

\section{Adherence questionnaires}

Adherence questionnaires were provided to physicians and patients. The physician's questionnaire contained questions regarding biomedical issues: time since HIV diagnosis, ART duration, current ART regimen, HIV transmission route, history of acquired immune deficiency syndrome (AIDS), comorbidities, co-medication, HIV-1 RNA VL, and CD4 cell count. The questionnaire was used to evaluate patient-, HIV-, and ART-related factors associated with nonadherence. Furthermore, the physicians were asked to classify their patients based on current and past adherence to one of the three adherence groups: A, good adherence; B, unstable adherence; $\mathrm{C}$, poor adherence. Patients with excellent history of adherence were classified as patients with "good adherence." Patients with intermittent phases of nonadherence were classified as patients with "unstable adherence." Finally, patients who could rarely adhere were classified as patients with poor adherence. Information on patients' age and sex was extracted from their medical records.

The patients' questionnaire was based on the German SMAQ MASRI Hybrid, ${ }^{22}$ which is a validated questionnaire. ${ }^{14,15}$ The patients' questionnaire included questions regarding the frequency and extent of nonadherence in three different time frames. In addition, it contained a list of reasons for nonadherent behavior, which was developed by our research group, as well as items regarding satisfaction with ART. Detailed information about the patient items is provided in Table 1. All questionnaires were prepared in the German language. The items were categorized, and some were renamed. For this study, items were translated into English.

\section{Study end points}

The outcomes of interest were as follows:

1. Concordance between physicians' adherence assessment and patients' self-reports of adherence, and its association with viral suppression.

2. Frequency and extent of nonadherent behavior in different time frames.

3. Patient-, HIV-, and ART-related factors associated with nonadherence based on physicians' adherence assessment.

4. Patients' self-reported reasons for nonadherent behavior and self-reported satisfaction with ART.

\section{Statistical analyses}

All results were expressed either in median and interquartile range (IQR), in number and percentage, or as odds ratio (OR) and 95\% confidence interval (95\% CI). First, the study population was characterized by describing sex, age, route 
Table I List of items in the patients' questionnaire

\begin{tabular}{|c|c|c|}
\hline Categorized items & Answers & Original text if renamed \\
\hline Number of missed doses & & Frequency of forgetting medication \\
\hline During the last month & $\begin{array}{l}\text { Less than I dose a month, } 2-3 \text { doses a } \\
\text { month, I-2 doses a week, nearly daily }\end{array}$ & $\begin{array}{l}\text { Less than once a month, } 2-3 \text { times a month, } \\
\text { I-2 times a week, nearly daily }\end{array}$ \\
\hline During the last week & No dose, I dose, 2 or more doses & Never, once, twice, more than two times \\
\hline During the last weekend & No dose, I dose, 2 doses & Never, once, twice \\
\hline \multicolumn{3}{|l|}{ Reasons for nonadherent behavior } \\
\hline \multicolumn{3}{|l|}{ Skipping medication when feeling bad } \\
\hline $\begin{array}{l}\text { Interactive toxicity beliefs regarding } \\
\text { alcohol or party drugs/going out }\end{array}$ & Yes/no & $\begin{array}{l}\text { I want to go out. I think my medication is not } \\
\text { compatible with alcohol/party drugs }\end{array}$ \\
\hline Reminder of the disease & & Taking ART reminds me of my disease \\
\hline No need of undergoing ART anymore & & It does not make sense anymore \\
\hline Harmfulness of ART & & The medication is harmful to me \\
\hline $\begin{array}{l}\text { Nonexistence of HIV; just exists for the } \\
\text { pharmaceutical industry to earn money }\end{array}$ & & $\begin{array}{l}\text { HIV does not exist; the pharmaceutical industry } \\
\text { just wants to earn money }\end{array}$ \\
\hline Afraid of being seen & & $\begin{array}{l}\text { I am afraid that others will see me taking my } \\
\text { medication }\end{array}$ \\
\hline Too high a dose & & I think the dose is too high \\
\hline Financial constraints & & $\begin{array}{l}\text { Co-payment is sometimes too expensive/other } \\
\text { financial reasons }\end{array}$ \\
\hline Other reasons & Free text field & \\
\hline \multicolumn{3}{|l|}{ Satisfaction with ART regarding } \\
\hline Interference with daily routine & Satisfied, not satisfied & Ordinal scale: $1-7 ; 1-2$ : satisfied, $3-7$ : not satisfied \\
\hline \multicolumn{3}{|l|}{ Efficacy } \\
\hline Simplicity & & Simplicity and acceptability \\
\hline \multicolumn{3}{|l|}{ Side effects } \\
\hline \multicolumn{3}{|l|}{ Other questions } \\
\hline Importance of regular ART intake & None/little, high, very high & None, little, high, very high \\
\hline Problems with adherence & Yes/no, free text field & \\
\hline
\end{tabular}

Note: List of categorized items from the patients' questionnaire, containing also the possible answers and the original text if the items or answers were renamed. Abbreviations: ART, antiretroviral therapy; HIV, human immunodeficiency virus.

of HIV transmission, history of AIDS, comorbidities, co-medication, time since HIV diagnosis, VL, CD4 cell count, current ART regimen, current ART dosing, and ART duration. Second, the concordance between physicians' adherence assessment and patients' self-reports of adherence was evaluated. We examined concordance between the categories "good adherence" in the physicians' assessment and "no missed dose during the last week" in the patients' questionnaire, as well as between "reduced adherence" (defined as unstable or poor adherence) and "one or more missed doses during the last week." All the previously mentioned concordant pairs were summed to describe the overall concordance of adherence assessment by physicians and patients. In addition, the association of physicians' adherence assessment with viral suppression $(<200 \mathrm{cp} / \mathrm{mL}$ vs $\geq 200 \mathrm{cp} / \mathrm{mL}$ ) was calculated. The Cohen's $\kappa$ test was used to measure agreement between physicians' adherence assessment and patients' self-reports of adherence and between physicians' adherence assessment and suppression of VL. Third, univariate descriptive analyses were conducted to compare patient-, HIV-, and ART-related factors between the three adherence groups: A, good vs B, unstable vs C, poor adherence. Medians were analyzed using the Kruskal-Wallis test, and percentages using the Fisher's extended exact test (Freeman-Halton test). In addition, binary multivariate logistic regression analyses were conducted using stepwise backward selection to assess the relationship between patient-, HIV-, and ART-related factors and "reduced adherence" (defined as unstable or poor). Covariates included in the logistic regression models were as follows: sex, age, route of HIV transmission, history of AIDS, comorbidities, co-medication, time since HIV diagnosis, and ART duration. Current ART regimen, VL, and CD4 cell count were not included in the model, because they were expected to be consequences of reduced adherence rather than causes for nonadherence and, therefore, constituted no proper variables for the model. We used stepwise backward selection until only variables with $p<0.05$ remained in the model. OR and $95 \%$ CI were reported for those covariates. In order to study patients' beliefs, the patients' self-reported reasons for nonadherent behavior were analyzed. After a general description of the reasons for nonadherent behavior, the frequency between the three groups was compared to focus on the barriers to adherence for patients with unstable or poor adherence. Finally, satisfaction with ART, pertaining 
to its interference with daily routine, efficacy, simplicity, and side effects, was examined. In all analyses, a $p$-value $<0.05$ was considered to be statistically significant. All statistical analyses were conducted using IBM SPSS Statistics Version 23 (IBM Corporation, Armonk, NY, USA).

\section{Results}

\section{Study population and adherence groups}

A total of 220 patients were enrolled at four German study centers. Due to protocol violation, five patients were excluded: one patient because of ART interruption, and the remaining four because of persistent detection of VLs despite ART duration for less than 6 months (Figure 1).

Therefore, 215 HIV-positive adults were included in the analyses: $80 \%$ were male, and the median age was 47 years (IQR 37-54). Additional characteristics of the study population are summarized in Table 2.

The physicians' adherence assessment between the three adherence groups showed the following: 75\% (162/215) in group A (good adherence), 17\% (36/215) in group B (unstable adherence), and $8 \%(17 / 215)$ in group $C$ (poor adherence).

\section{Concordance of physicians' adherence assessment with patients' self-reports of adherence and its association with viral suppression}

The adherence of 162 patients was described as good by their physicians. Of those patients, $90 \%(n=145)$ reported "no dose missed during the last week," while $10 \%(n=17)$ reported "one or more doses missed during the last week." The adherence of 53 patients was described as "reduced" (unstable, $\mathrm{n}=36$; poor, $\mathrm{n}=17)$. Of those patients, $48 \%(\mathrm{n}=25)$ reported "no dose missed during the last week," while 52\% $(n=27)$ reported "one or more missed doses during the last week;"

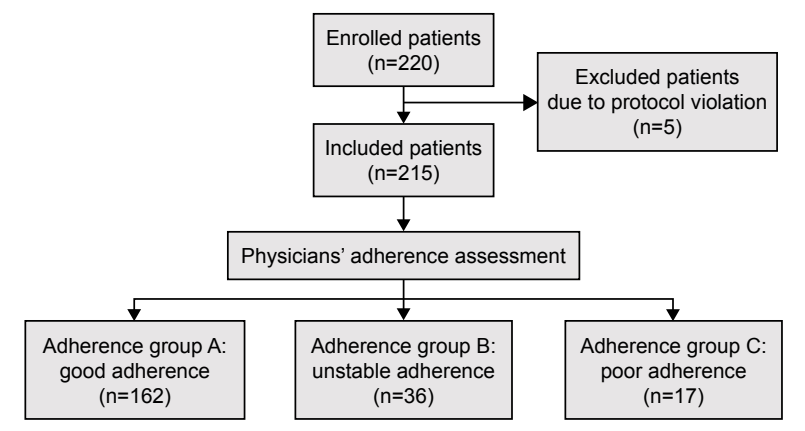

Figure I Flowchart of the process of patients' inclusion and categorization into adherence groups A, B, and C (good, unstable, or poor adherence, respectively), based on physicians' adherence assessment.
Table 2 Overview of the characteristics of the participants included in the analyses, with patient-, HIV-, and ART-related factors

\begin{tabular}{|c|c|c|c|}
\hline Items & $\mathbf{n}$ & $\%$ & Median (IQR) \\
\hline \multicolumn{4}{|l|}{ Patient-related factors } \\
\hline Male sex & 172 & 80 & \\
\hline Age (years) & & & $47(37-54)$ \\
\hline \multicolumn{4}{|l|}{ HIV transmission route } \\
\hline MSM & 108 & 50 & \\
\hline Origin of HPC & 29 & 14 & \\
\hline IVDU & 15 & 7.0 & \\
\hline Other & 27 & 13 & \\
\hline Unknown & 39 & 18 & \\
\hline Comorbidities & 161 & 75 & \\
\hline Psychiatric disorder & 63 & 29 & \\
\hline Depression & 40 & 19 & \\
\hline HBV & 10 & 4.7 & \\
\hline $\mathrm{HCV}$ & 13 & 6.0 & \\
\hline Cardiovascular risk factors & 51 & 24 & \\
\hline Major vascular event & 11 & 5.1 & \\
\hline Other & 108 & 50 & \\
\hline Co-medication & 93 & 43 & \\
\hline Psychiatric co-medication & 24 & II & \\
\hline Cardiovascular co-medication & 50 & 23 & \\
\hline Antiinfectives & 16 & 7.4 & \\
\hline Other & 48 & 22 & \\
\hline \multicolumn{4}{|l|}{ HIV-related factors } \\
\hline Time since HIV diagnosis (years) & & & $9(4-18)$ \\
\hline History of AIDS & 24 & 11 & \\
\hline HIV-I RNA VL (cp/mL) & & & $19(19-49)$ \\
\hline CD4 cells $(n / \mu \mathrm{L})$ & & & $607(410-850)$ \\
\hline \multicolumn{4}{|l|}{ ART-related factors } \\
\hline ART duration (years) & & & $6(3-14)$ \\
\hline \multicolumn{4}{|l|}{ ART dosing and pill burden } \\
\hline STR & 65 & 30 & \\
\hline MTR once daily & 103 & 48 & \\
\hline MTR twice daily & 47 & 22 & \\
\hline \multicolumn{4}{|l|}{ Current ART regimen } \\
\hline NRTI containing & 192 & 89 & \\
\hline NNRTI containing & 90 & 42 & \\
\hline PI containing & 75 & 35 & \\
\hline CCR5 containing & 2 & 0.9 & \\
\hline INI containing & 69 & 32 & \\
\hline
\end{tabular}

Abbreviations: AIDS, acquired immune deficiency syndrome; ART, antiretroviral therapy; CCR5, C-C chemokine receptor 5 inhibitor; cp, copies; HBV, chronic hepatitis B infection; HCV, chronic hepatitis C infection; HIV, human immunodeficiency virus; HPC, high prevalence country; IQR, interquartile range; INI, integrase inhibitor; IVDU, intravenous drug use; MSM, men having sex with men; MTR, multi-tablet regimen; NNRTI, non-nucleoside reverse transcriptase inhibitor; NRTI, nucleoside reverse transcriptase inhibitor; PI, protease inhibitor; STR, singletablet regimen; VL, viral load.

one answer was missing. Of all patients, $68 \%(n=145)$ were assessed by both physicians and themselves as adherent, while $13 \%$ of all patients $(n=27)$ were assessed by both physicians and themselves as nonadherent. Therefore, concordance of physicians' adherence assessment and patients' self-reports of adherence was $81 \%$. All numbers are provided in Table 3 . The $\kappa$ value for agreement was -0.090 . 
Table 3 Concordance of physicians' adherence assessment and patients' self-reports

\begin{tabular}{l|l|l}
\hline & $\begin{array}{l}\text { Physicians' adherence } \\
\text { assessment, } \mathbf{n} \\
\text { (\% of whole study group) }\end{array}$ & \\
\cline { 2 - 3 } & Good Unstable/poor & \\
\hline $\begin{array}{l}\text { Patients' self-reports, } \\
\mathbf{n} \text { (\% of whole study } \\
\text { group) }\end{array}$ & $25(11.7)$ & $170(79.4)$ \\
$\begin{array}{l}\text { No dose missed } \\
\text { during the last week } \\
\text { One or more doses } \\
\text { missed during the } \\
\text { last week }\end{array}$ & $145(67.8) \quad 27(12.6)$ & $44(20.6)$ \\
\hline & $162(75.7)^{\mathrm{a}} \quad 52(24.3)$ & $214(100)$ \\
\hline
\end{tabular}

Note: a One patient's data was missing.

Of the 162 patients with good adherence, 99\% $(\mathrm{n}=160)$ had a $V L<200 \mathrm{cp} / \mathrm{mL}$, while $1.2 \%(\mathrm{n}=2)$ had a $\mathrm{VL} \geq 200 \mathrm{cp} / \mathrm{mL}$. Of the 53 patients with reduced adherence, $70 \%(\mathrm{n}=37)$ had a VL $<200 \mathrm{cp} / \mathrm{mL}$, while $30 \%(\mathrm{n}=16)$ had a $V L \geq 200 \mathrm{cp} / \mathrm{mL}$. Seventy-four percent of all patients $(n=160)$ were described by physicians as adherent and had a VL $<200 \mathrm{cp} / \mathrm{mL}$, while $7.4 \%$ of all patients $(\mathrm{n}=16)$ were described by physicians as nonadherent and had a VL $\geq 200$ $\mathrm{cp} / \mathrm{mL}$. The $\kappa$ value for agreement was 0.372 .

\section{Differences in patients' self-reports of adherence in relation to the evaluated time frame}

Concurrent with results from physicians' assessment regarding reduced adherence, a higher percentage of patients in groups B and C reported missing doses in all three time frames: regarding the doses missed during the last month, a higher percentage of patients from groups $\mathrm{B}$ and $\mathrm{C}$ reported "missed one or more doses per week" (A: 2.5\% [4/162] vs B: $8.3 \%$ [3/36] vs C: $24 \%$ [4/17], $p<0.001)$. Regarding the doses missed during the last week, an even higher percentage of patients from groups $\mathrm{B}$ and $\mathrm{C}$ reported "missed one or more doses" (A: 11\% [17/162] vs B: 47\% [17/36] vs C: $63 \%[10 / 17], p<0.001)$. Regarding the doses missed during the last weekend, the percentage of patients from groups B and $\mathrm{C}$ who reported "one or more missed doses" was still significantly high (A: 3.1\% [5/162] vs B: $22 \%$ [8/36] vs C: $31 \%[5 / 17], p<0.001)$.

\section{Factors associated with reduced adherence}

Table 4 summarizes the patient-, HIV-, and ART-related factors in the three adherence groups. Significant differences between the three groups regarding the following patientrelated factors are: age, HIV transmission route, chronic hepatitis $\mathrm{C}$ infection (HCV), and psychiatric disorders. Furthermore, Table 4 summarizes the significant differences between the groups regarding the following HIV- and ART-related factors: time since HIV diagnosis, history of AIDS, VL, CD4 cell count, ART duration, and current ART regimen. Sex, co-medication, and dosing frequency did not show significant differences between groups.

Multivariate regression analysis showed that the following variables remained significantly associated with reduced adherence, defined as unstable or poor: age $<30$ years $(\mathrm{OR}=4.2,95 \%$ CI 1.4-12.6, $p=0.010)$, HIV transmission via intravenous drug use (IVDU; OR $=16.7,95 \%$ CI 4.2-66.2, $p<0.001$ ), history of AIDS (OR $=5.8,95 \%$ CI 2.2-15.3, $p<0.001)$, and psychiatric disorders (OR $=2.5,95 \% \mathrm{CI}$ $1.2-5.4, p=0.015)$.

\section{Self-reported reasons for nonadherent behavior}

A higher proportion of patients from adherence groups $B$ and $\mathrm{C}$ than from group $\mathrm{A}$ reported reasons for adherence problems (A: 32\% [52/162] vs B: 78\% [24/36] vs C: $94 \%$ [16/17], $p<0.001)$. In general, the most frequently reported reasons were as follows: just forgot $(n=16)$, reminder of the disease $(n=16)$, skipping medication when feeling bad $(n=13)$, stress/stressful work $(n=12)$, interactive toxicity beliefs regarding alcohol or party drugs/going out $(n=12)$, different daily routine $(n=10)$, and afraid of being seen $(\mathrm{n}=10)$. "Skipping medication when feeling bad," "reminder of the disease," "interactive toxicity beliefs regarding alcohol or party drugs/going out," "too high a dose," "afraid of being seen," "no need of undergoing ART anymore," and "financial constraints" were the reasons reported significantly more often by groups $\mathrm{B}$ and $\mathrm{C}$ patients than by the group $\mathrm{A}$ patients, as shown in Figure 2.

\section{Patient satisfaction with ART and its association with adherence}

A higher percentage of patients from adherence groups $B$ and $C$ reported that they were not satisfied with ART regarding interference with daily routine, efficacy, simplicity, and side effects. While dissatisfaction regarding interference with daily routine, efficacy, and simplicity was significantly associated with unstable and poor adherence, dissatisfaction regarding side effects was not significantly associated with unstable or poor adherence, as summarized in Table 5. 
Table 4 Patient-, HIV-, and ART-related factors correlated with "unstable" or "poor adherence"

\begin{tabular}{|c|c|c|c|c|c|c|c|}
\hline \multirow[t]{3}{*}{ Item } & \multicolumn{6}{|c|}{ Physicians' adherence assessment } & \multirow[t]{3}{*}{$p$-value } \\
\hline & \multicolumn{2}{|c|}{$\begin{array}{l}\text { Good adherence } \\
(n=162)\end{array}$} & \multicolumn{2}{|c|}{$\begin{array}{l}\text { Unstable adherence } \\
(n=36)\end{array}$} & \multicolumn{2}{|c|}{$\begin{array}{l}\text { Poor adherence } \\
(n=\mid 7)\end{array}$} & \\
\hline & $\mathbf{n}$ & $\%$ & $\mathbf{n}$ & $\%$ & $\mathbf{n}$ & $\%$ & \\
\hline \multicolumn{8}{|l|}{ Patient-related factors } \\
\hline Male sex & 132 & 82 & 28 & 78 & 12 & 71 & 0.479 \\
\hline Age $(\text { years })^{\mathrm{a}}$ & 48 & $40-55$ & 42 & $33-51$ & 46 & $44-48$ & 0.020 \\
\hline$<30$ & 10 & 6.2 & 6 & 17 & I & 5.9 & 0.120 \\
\hline$\geq 30$ & 152 & 93.8 & 30 & 83 & 16 & 94 & \\
\hline \multicolumn{8}{|l|}{ Transmission route } \\
\hline MSM & 91 & 56 & 13 & 36 & 4 & 24 & 0.007 \\
\hline Transmission in HPC & 17 & 11 & 7 & 19 & 5 & 29 & 0.040 \\
\hline IVDU & 3 & 1.9 & 8 & 22 & 4 & 24 & $<0.001$ \\
\hline Other & 19 & 12 & 5 & 14 & 3 & 18 & 0.631 \\
\hline Unknown & 33 & 20 & 5 & 14 & I & 5.9 & 0.303 \\
\hline \multicolumn{8}{|l|}{ Comorbidities } \\
\hline Psychiatric disorder & 40 & 25 & 15 & 42 & 8 & 47 & 0.030 \\
\hline HBV & 7 & 4.3 & 3 & 8.3 & 0 & 0 & 0.494 \\
\hline $\mathrm{HCV}$ & 6 & 3.7 & 6 & 17 & I & 5.9 & 0.013 \\
\hline Cardiovascular risk factors & 41 & 25 & 8 & 22 & 2 & 12 & 0.527 \\
\hline Major vascular event & 9 & 5.6 & I & 2.8 & I & 5.9 & 0.758 \\
\hline Other & 89 & 55 & 13 & 36 & 6 & 35 & 0.052 \\
\hline \multicolumn{8}{|l|}{ Co-medication } \\
\hline Psychiatric & 17 & 11 & 6 & 17 & I & 5.9 & 0.514 \\
\hline Cardiovascular & 41 & 25 & 8 & 22 & I & 5.9 & 0.226 \\
\hline Antiinfectives & 9 & 5.6 & 6 & 17 & I & 5.9 & 0.079 \\
\hline Other & 35 & 22 & 10 & 28 & 3 & 18 & 0.687 \\
\hline \multicolumn{8}{|l|}{ HIV-related factors } \\
\hline Time since HIV diagnosis (years) ${ }^{\mathrm{a}}$ & 9 & $4-16$ & 10 & $5-21$ & 19 & $|5-2|$ & 0.002 \\
\hline$<1$ & 6 & 3.8 & I & 2.9 & 0 & 0 & 0.024 \\
\hline $1-10$ & 89 & 56 & 17 & 49 & 3 & 17 & \\
\hline$>10$ & 65 & 41 & 17 & 49 & 14 & 82 & \\
\hline History of AIDS & II & 6.8 & 9 & 25 & 4 & 24 & 0.002 \\
\hline HIV-I RNA VL $(c p / m L)^{a}$ & 19 & $19-39$ & 49 & $19-49$ & 4,824 & $60-17,542$ & $<0.001$ \\
\hline CD4 cell count $(n / \mu L)^{a}$ & 680 & $487-887$ & 503 & $2|1-76|$ & 315 & $86-426$ & $<0.001$ \\
\hline \multicolumn{8}{|l|}{ ART-related factors } \\
\hline ART duration (years) ${ }^{\mathrm{a}}$ & 6 & $3-12$ & 5 & $3-11$ & 14 & $9-17$ & 0.022 \\
\hline$<1$ & 10 & 6.3 & 3 & 8.6 & 0 & 0 & 0.142 \\
\hline $1-10$ & 103 & 64 & 23 & 66 & 7 & 41 & \\
\hline$>10$ & 47 & 29 & 9 & 26 & 10 & 59 & \\
\hline \multicolumn{8}{|l|}{ ART dosing and pill burden } \\
\hline STR & 50 & 31 & 13 & 36 & 2 & 12 & 0.173 \\
\hline MTR once daily & 78 & 48 & 16 & 44 & 9 & 53 & $0.84 I$ \\
\hline MTR twice daily & 34 & 21 & 7 & 19 & 6 & 35 & 0.373 \\
\hline \multicolumn{8}{|l|}{ Current ART regimen } \\
\hline NRTI containing & 143 & 88 & 34 & 94 & 15 & 88 & 0.629 \\
\hline NNRTI containing & 79 & 49 & 10 & 28 & 1 & 5.9 & $<0.001$ \\
\hline PI containing & 46 & 28 & 17 & 47 & 12 & 71 & 0.001 \\
\hline CCR5 containing & 2 & 1.2 & 0 & 0 & 0 & 0 & I \\
\hline INI containing & 52 & 32 & 11 & 31 & 6 & 35 & 0.936 \\
\hline
\end{tabular}

Note: $p$-values were calculated using the Fisher's extended exact and Kruskal-Wallis test. ${ }^{\text {a Data }}$ presented as median and IQR.

Abbreviations: AIDS, acquired immune deficiency syndrome; ART, antiretroviral therapy; CCR5, C-C chemokine receptor 5 inhibitor; cP, copies; HBV, chronic hepatitis B infection; HCV, chronic hepatitis C infection; HIV, human immunodeficiency virus; HPC, high prevalence country; IQR, interquartile range; INI, integrase inhibitor; IVDU, intravenous drug use; MSM, men having sex with men; MTR, multi-tablet regimen; NNRTI, non-nucleoside reverse transcriptase inhibitor; NRTI, nucleoside reverse transcriptase inhibitor; PI, protease inhibitor; STR, single-tablet regimen; VL, viral load.

A higher percentage of patients from groups $\mathrm{B}$ and $\mathrm{C}$ agreed having problems with adherence (A: $8.6 \%[14 / 162]$ vs B: $14 \%$ [5/35] vs C: $35 \%$ [6/17], $p=0.008)$. Recognized problems included: aversion to pill swallowing $(n=3)$, side effects $(n=4)$, irregular daily routine $(n=1)$, negligence $(\mathrm{n}=1)$, and problems with dietary restrictions $(\mathrm{n}=1)$. A lower percentage of patients from groups $\mathrm{B}$ and $\mathrm{C}$ rated the importance of regular intake of medication as very high 


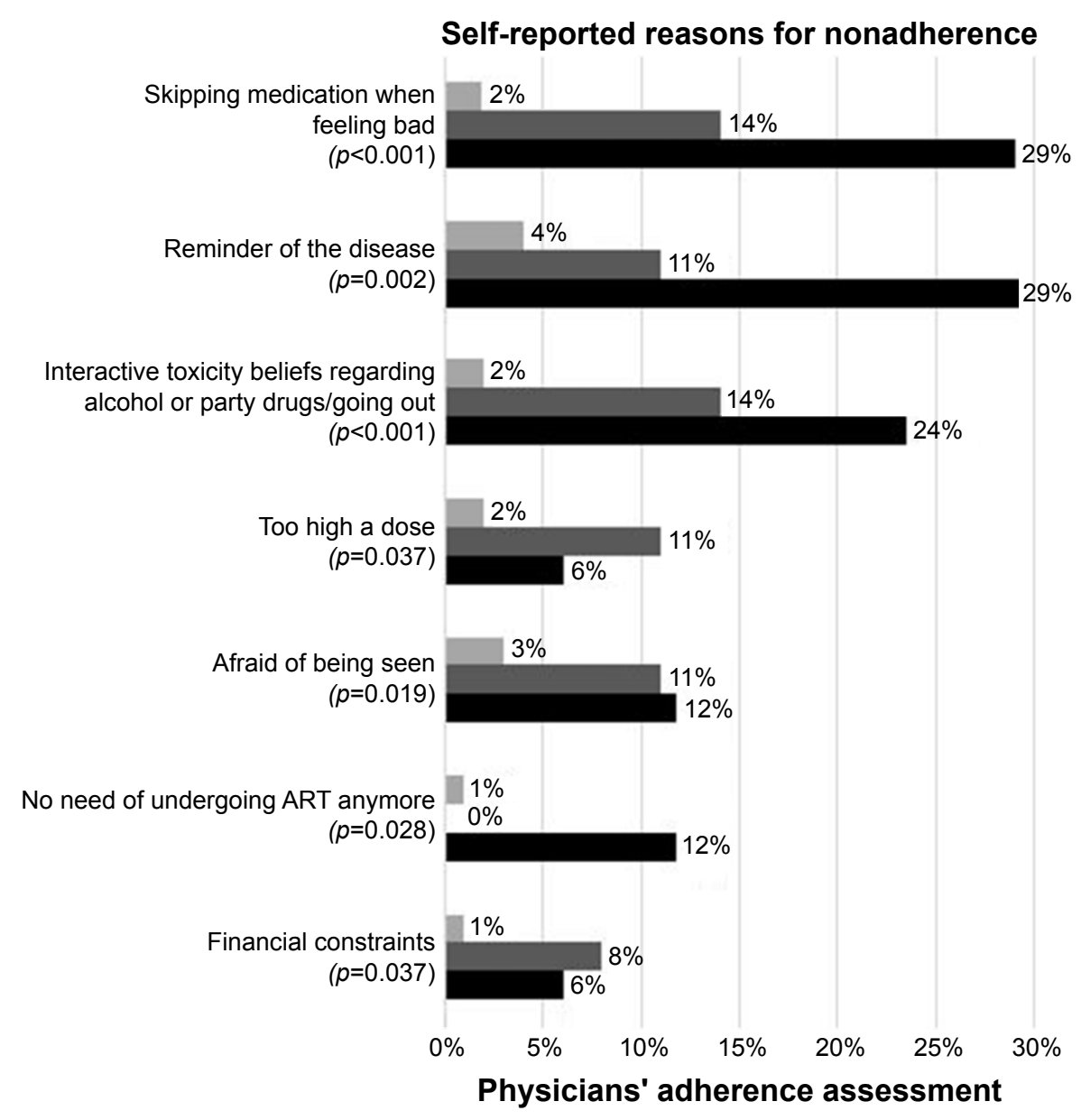

A: good adherence $(n=162) \square$ B: unstable adherence $(n=36) \square$ C: poor adherence $(n=17)$

Figure 2 Differences in self-reported reasons for nonadherent behavior between the adherence groups.

Note: $p$-values were calculated using the Fisher's extended exact test.

Abbreviation: ART, antiretroviral therapy.

(A: $83 \%$ [133/162] vs B: $66 \%$ [23/36] vs C: $71 \%$ [12/17], $p=0.033$ ).

\section{Discussion}

This cross-sectional study provides insights into the factors associated with a higher risk of nonadherence and into

Table 5 Association of patient dissatisfaction with ART and nonadherence

\begin{tabular}{|c|c|c|c|c|c|c|c|}
\hline \multirow{3}{*}{$\begin{array}{l}\text { Patient } \\
\text { dissatisfaction } \\
\text { regarding }\end{array}$} & \multicolumn{6}{|c|}{ Physicians' adherence assessment } & \multirow[t]{3}{*}{ p-value } \\
\hline & \multicolumn{2}{|c|}{$\begin{array}{l}\text { Good } \\
\text { adherence } \\
(n=162) \\
\end{array}$} & \multicolumn{2}{|c|}{$\begin{array}{l}\text { Unstable } \\
\text { adherence } \\
(n=36)\end{array}$} & \multicolumn{2}{|c|}{$\begin{array}{l}\text { Poor } \\
\text { adherence } \\
(n=17)\end{array}$} & \\
\hline & $\mathbf{n}$ & $\%$ & $\mathbf{n}$ & $\%$ & $\mathbf{n}$ & $\%$ & \\
\hline $\begin{array}{l}\text { Interference with } \\
\text { daily routine }\end{array}$ & 16 & 9.9 & 9 & 25.0 & 6 & 35.3 & 0.003 \\
\hline Efficacy & 3 & 1.9 & 4 & II.I & $\mathrm{I}$ & 5.9 & 0.001 \\
\hline Simplicity & 6 & 3.7 & 6 & 16.7 & 2 & 11.8 & 0.018 \\
\hline Side effects & 26 & 16.0 & 9 & 25.0 & 6 & 35.0 & 0.218 \\
\hline
\end{tabular}

Abbreviation: ART, antiretroviral therapy. the self-reported reasons for nonadherence. Physicians correlate extensive information, including the frequency of nonadherence and reasons for nonadherent behavior, that are collected over a long time during patient interviews, with patients' VL. ${ }^{23-25}$ This provides a long-term, multidimensional overview of adherence. Therefore, physicians' adherence assessment was used to classify adherence groups, although this may be subjective. In our study, physicians' adherence assessment and patients' self-reports of missed doses showed good concordance. In addition, there was a strong association of physicians' adherence assessment with patients' viral suppression. However, the $\kappa$ values estimating the agreement between the various methods of adherence assessment were poor, especially for agreement between physicians' adherence assessment and self-report, which is consistent with previous reports. ${ }^{25}$ The poor $\kappa$ values seem to be mainly due to the disagreement in the nonadherence assessment. Of note, the $\kappa$ statistics may be affected by the 
lack of symmetry and by imbalances in the marginal totals of the $2 \times 2$ tables and therefore may not be the appropriate measurement for interrater agreement in this situation. ${ }^{26}$ The disagreement in the nonadherence assessment may be due to patients' overestimation of adherence, ${ }^{11,12,27}$ alternate phases of high and low adherence, or erroneous physicians' adherence assessment. The analysis of patients' self-reports of adherence showed that the number of missed doses during the last week was higher in the self-reports of "last week" than in the ones of "last month." Therefore, we hypothesized the self-reports of last week were more accurate, probably due to recall bias.

Consistent with previous studies, ${ }^{28,29}$ the majority of included patients was adherent; however, we revealed a remarkable number of nonadherent patients in our study. Because our study aimed at including more patients with adherence problems, the frequency of nonadherence in our cohort does not represent the overall HIV population in Germany.

Our multivariate analyses demonstrated that reduced adherence was associated with known patient-related factors such as younger age, , 5,13,30-32 history of hard drug use, ,,6,31,33-36 and psychiatric disorders (especially depression). ${ }^{27,37-43}$ Our study also revealed a correlation between the history of AIDS and reduced adherence. This is probably due to the physicians' adherence assessment that included the patients' entire history over a long period of time. In accordance with various studies, our study did not find a correlation between female individuals and reduced adherence..$^{5,31,34,44}$

In line with the studies by Langness et $\mathrm{al}^{19}$ and Saberi et al, ${ }^{46}$ dissatisfaction with regimen complexity and interference with daily routine was associated with unstable or poor adherence in our study. In contrast, patient dissatisfaction with side effects was not significantly associated with unstable or poor adherence. Therefore, due to lower dosing frequencies and less side effects, it remains unclear whether pharmaceutical reasons for nonadherence are still as important as they used to be.

In addition to studying patient-, HIV-, and ART-related factors, we further analyzed the patients' reasons for nonadherent behavior. We hypothesized that there may be an association of unstable or poor adherence with patients' beliefs. Patients' beliefs are found to be crucial to adherence intervention strategies because they are reported to be frequent among patients and may be targeted to enhance adherence - in contrast to most patient-, HIV-, and ART-related factors. ${ }^{27,45}$

In this study, patients reported a vast variety of reasons for nonadherence. We focused on the reasons given by patients with unstable or poor adherence and found that those patients reported unspecific answers, such as just forgot or stress/stressful work, less frequently than patients with good adherence. We found a correlation between unstable or poor adherence and questioning ART efficacy and correct dosage, in agreement with Saberi et al. ${ }^{46}$ We also found that unstable or poor adherence correlated with "interactive toxicity beliefs regarding alcohol or party drugs/going out." It has already been observed that patients may intentionally skip ART doses when they consume alcohol or drugs. ${ }^{47-51}$ It is a common misperception that alcohol inhibits ART's effectiveness and that there are potential toxic interactions between ART and alcohol consumption. ${ }^{47-49}$ Probably, physicians avoid talking about the alcohol-ART interaction or even tell their patients not to take alcohol with their ART. ${ }^{47,49,51}$ A discussion to clarify the interaction between ART and alcohol, and other recreational drugs, may be highly beneficial to maximize adherence.

There are several limitations to our study. Although we encouraged participation of nonadherent patients, we could not include as many as expected. The sample of patients with poor adherence was especially small, due to low prevalence of nonadherence and to little motivation of those patients to participate in a study. Even though the physicians' assessment offers a relevant view of adherence, such assessments are not free from personal biases and may be influenced by VL results. Furthermore, self-reported nonadherence and reasons for nonadherence may be underreported due to poor recall and social desirability bias. No detailed information about recent alcohol consumption and hard drug use was collected in our study because we assumed that this information will be strongly underreported. Because this is an observational, cross-sectional study, no causal conclusions can be drawn and one should be cautious when generalizing these results to the overall German HIV population.

\section{Conclusion}

A remarkable number of patients with unstable or poor adherence were identified in our study. In every case, physicians should evaluate patients' adherence during a short time frame to reduce recall bias. While recognition of factors associated with nonadherence helps identifying patients with a higher risk of nonadherence, it is more important to address patients' individual reasons for nonadherent behavior, such as interactive toxicity beliefs, HIV stigma, and concerns about drug dosage. In nonadherent patients, specific reasons for nonadherent behaviors are common and may be targeted for interference, thus representing potential starting points for focused counseling and adherence interventions. Further investigation is required to reveal how to optimize patient-health care provider relationships and how to unveil 
and solve adherence problems, thus achieving long-term viral suppression and avoiding disease progression.

\section{Acknowledgments}

The authors would like to express their gratitude to all respondents who participated in the study. This work was supported by the German Research Foundation (DFG) and the Technical University of Munich. Part of this work was presented at HIV Drug Therapy Glasgow 2016, October 23, 2016, to October 26, 2016, UK, P060. We would like to acknowledge the Department of Medicine II, University Hospital Klinikum rechts der Isar, MVZ Karlsplatz, HIV Clinical Care Center, Center of Infectiology Prenzlauer Berg, Private Practice, Zentrum fuer Innere Medizin und Infektiologie, Private Practice, and Department of Dermatology and Allergology, University Hospital Klinikum rechts der Isar, for participating and recruiting patients for the study. The contributions of MUC Research in the support of statistical analyses are also very gratefully acknowledged. The datasets used and analyzed during the current study are available upon reasonable request to the corresponding author Johanna Boretzki.

\section{Author contributions}

$\mathrm{CDS}, \mathrm{CW}, \mathrm{AB}$, and EW developed the study design and used the questionnaires. $\mathrm{CDS}, \mathrm{CW}, \mathrm{AM}, \mathrm{IK}, \mathrm{AZ}, \mathrm{SN}$, and JB recruited the patients for the study and performed the questionnaires. $\mathrm{AB}, \mathrm{EW}$, and $\mathrm{JB}$ conducted the statistical analyses of the data and interpreted the results together with CDS, CW, and CL. CDS, EW, AB, SN, and JB were the major contributors in writing the manuscript. All authors contributed toward data analysis, drafting and critically revising the paper and agree to be accountable for all aspects of the work. All the authors read and approved the final version of the manuscript.

\section{Disclosure}

$\mathrm{CW}$ received travel grants from AbbVie, Bristol-Meyers Squibb, Gilead Science, and Jansen. AZ received travel grants from AbbVie, Bristol-Meyers Squibb, Gilead Sciences, and MSD. IK received travel grants from ViiV, Abbvie, MDS, Gilead, and Bristol-Meyers Squibb. The other authors report no conflicts of interest in this work.

\section{References}

1. Ledergerber B, Cavassini M, Battegay M, et al; Swiss HIV Cohort Study. Trends over time of virological and immunological characteristics in the Swiss HIV cohort study. HIV Med. 2011;12(5):279-288.

2. Hogg R. Life expectancy of individuals on combination antiretroviral therapy in high-income countries: a collaborative analysis of 14 cohort studies. Lancet. 2008;372(9635):293-299.
3. Viswanathan S, Justice AC, Alexander GC, et al. Adherence and HIV RNA suppression in the current era of highly active antiretroviral therapy. J Acquir Immune Defic Syndr. 2015;69(4):493-498.

4. Gulick RM. Adherence to antiretroviral therapy: how much is enough? Clin Infect Dis. 2006;43(7):942-944.

5. Safren SA, Biello KB, Smeaton L, et al. PEARLS (ACTG A5175) Study Team. Psychosocial predictors of non-adherence and treatment failure in a large scale multi-national trial of antiretroviral therapy for HIV: data from the ACTG A5175/PEARLS trial. PLoS One. 2014; 9(8): $1-10$.

6. Sax PE, Meyers JL, Mugavero M, Davis KL. Adherence to antiretroviral treatment and correlation with risk of hospitalization among commercially insured HIV patients in the United States. PLoS One. 2012; $7(2):$ e31591

7. Simoni JM, Kurth AE, Pearson CR, Pantalone DW, Merrill JO, Frick PA Self-report measures of antiretroviral therapy adherence: a review with recommendations for HIV research and clinical management. AIDS Behav. 2006;10(3):227-245.

8. Liu H, Miller LG, Hays RD, et al. Repeated measures longitudinal analyses of HIV virologic response as a function of percent adherence, dose timing, genotypic sensitivity, and other factors. $J$ Acquir Immune Defic Syndr. 2006;41(3):315-322.

9. Lima VD, Harrigan R, Bangsberg DR, et al. The combined effect of modern highly active antiretroviral therapy regimens and adherence on mortality over time. J Acquir Immune Defic Syndr. 2009;50(5): 529-536.

10. Bangsberg DR, Hecht FM, Charlebois ED, et al. Adherence to protease inhibitors, HIV-1 viral load, and development of drug resistance in an indigent population. AIDS. 2000;14(4):357-366.

11. Osterberg L, Blaschke T. Adherence to medication. NEngl J Med. 2005; 335(5):487-497.

12. Arnsten JH, Demas PA, Farzadegan H, et al. Antiretroviral therapy adherence and viral suppression in HIV-infected drug users: comparison of self-report and electronic monitoring. Clin Infect Dis. 2001; 33(8):1417-1423.

13. Glass TR, De Geest S, Weber R, et al. Correlates of self-reported nonadherence to antiretroviral therapy in HIV-infected patients: the Swiss HIV cohort study. J Acquir Immune Defic Syndr. 2006;41(3):385-392.

14. Knobel H, Alonso J, Casado JL, et al; GEEMA Study Group. Validation of a simplified medication adherence questionnaire in a large cohort of HIV-infected patients: the GEEMA Study. AIDS. 2002;16(4): 605-613.

15. Walsh JC, Mandalia S, Gazzard BG. Responses to a 1 month self-report on adherence to antiretroviral therapy are consistent with electronic data and virological treatment outcome. AIDS. 2002;16(2):269-277.

16. Reynolds NR, Sun J, Nagaraja HN, Gifford AL, Wu AW, Chesney MA. Optimizing measurement of self-reported adherence with the ACTG adherence questionnaire: a cross-protocol analysis. $J$ Acquir Immune Defic Syndr. 2007;46(4):402-409.

17. Steiner JF. Rethinking adherence. Ann Intern Med. 2012;157(15): 580-585.

18. Sabaté E [webpage on the Internet]. Adherence to Long-Term Therapies - Evidence for Action. World Health Organization; 2003. Available from: http://www.who.int/chp/knowledge/publications/ adherence_report/en/. Accessed February 25, 2016.

19. Langness J, Cook PF, Gill J, Boggs R, Netsanet N. Comparison of adherence rates for antiretroviral, blood pressure, or mental health medications for HIV-positive patients at an academic medical center outpatient pharmacy. J Manag Care Pharm. 2014;20(8):809-814.

20. Cohen CJ, Meyers JL, Davis KL. Association between daily antiretroviral pill burden and treatment adherence, hospitalisation risk, and other healthcare utilisation and costs in a US medicaid population with HIV. BMJ Open. 2013;3(8):1-13.

21. Raffi F, Yazdanpanah Y, Fagnani F, Laurendeau C, Lafuma A, Gourmelen J. Persistence and adherence to single-tablet regimens in HIV treatment : a cohort study from the French National Healthcare Insurance Database. J Antimicrob Chemother. 2015;70(7):2121-2128. 
22. Kuhlmann B, Liess H. Leitlinien Der DAGNÄ Zur Unterstützung der Adhärenz im Rahmen einer antiretroviralen Therapie bei HIVInfektion [Guidelines of the DAGNÄ to support adherence to antiretroviral therapy in HIV positive patients]. 2004. Available from: http:// www.kompetenznetz-hiv.de/media/Leitlinie_Adhaerenz_ART_-_ Stand_2004-09_DAGNAE.pdf. Accessed Sept 15, 2017.

23. Mekuria LA, Prins JM, Yalew AW, Sprangers MA, Nieuwkerk PT. Which adherence measure - self-report, clinician recorded or pharmacy refill - is best able to predict detectable viral load in a public ART programme without routine plasma viral load monitoring? Trop Med Int Health. 2016;21(7):856-869.

24. Farley J, Hines S, Musk A, Ferrus S, Tepper V. Assessment of adherence to antiviral therapy in HIV-infected children using the medication event monitoring system, pharmacy refill, provider assessment, caregiver self-report, and appointment keeping. J Acquir Immune Defic Syndr. 2003;33(2):211-218.

25. Wagner JH, Justice AC, Chesney M, Sinclair G, Weissman S, Rodriguez-Barradas MC. Patient- and provider-reported adherence: toward a clinically useful approach to measuring antiretroviral adherence. J Clin Epidemiol. 2001;54(1):91-98.

26. Shankar V, Bangdiwala SI. Observer agreement paradoxes in $2 \times 2$ tables: comparison of agreement measures. BMC Med Res Methodol. 2014;14(100):1-9.

27. Langebeek N, Gisolf EH, Reiss P, et al. Predictors and correlates of adherence to combination antiretroviral therapy (ART) for chronic HIV infection: a meta-analysis. BMC Med. 2014;12(142):1-14.

28. Biswas B, Spitznagel E, Collier AC, et al; The CHARTER Group. Characterizing HIV medication adherence for virologic success among individuals living with HIV/AIDS: experience with the CNS HIV antiretroviral therapy effects research (CHARTER) cohort. J HIV AIDS Soc Serv. 2014;13(1):8-25.

29. Lima VD, Bangsberg DR, Harrigan PR, Deeks SG, Hogg RS, Montaner JSG. Risk of viral failure declines with duration of suppression on HAART, irrespective of adherence level viviane. $J$ Acquir Immune Defic Syndr. 2010;55(4):460-465.

30. Cambiano V, Lampe FC, Rodger AJ, et al. Long-term trends in adherence to antiretroviral therapy from start of HAART. AIDS. 2010;24(8): 1153-1162.

31. Mannheimer S, Friedland G, Matts J, Child C, Chesney M. The consistency of adherence to antiretroviral therapy predicts biologic outcomes for human immunodeficiency virus-infected persons in clinical trials. Clin Infect Dis. 2002;34(8):1115-1121.

32. Raboud J, Li M, Walmsley S, et al. Once daily dosing improves adherence to antiretroviral therapy. AIDS Behav. 2011;15(7): $1397-1409$

33. Ortego C, Huedo-Medina TB, Llorca J, et al. Adherence to highly active antiretroviral therapy (HAART): a meta-analysis. AIDS Behav. 2011; 15(7):1381-1396.

34. Cantudo-Cuenca MR, Jimenez-Galan R, Almeida-Gonzalez CV, Morillo-Verdugo R. Concurrent use of comedications reduces adherence to antiretroviral therapy among HIV-infected patients. $J$ Manag Care Spec Pharm. 2014;20(8):844-850.

35. Cohn SE, Jiang H, McCutchan JA, et al. Association of ongoing drug and alcohol use with non-adherence to antiretroviral therapy and higher risk of AIDS and death: results from ACTG 362. AIDS Care. 2011;23(6):775-785.
36. Nahvi S, Litwin AH, Heo M, Berg KM, Li X, Arnsten JH. Directly observed antiretroviral therapy eliminates adverse effects of active drug use on adherence. Drug Alcohol Depend. 2012;120(1-3):174-180.

37. Sayles JN, Wong MD, Kinsler JJ, Martins D, Cunningham WE. The association of stigma with self-reported access to medical care and antiretroviral therapy adherence in persons living with HIV/AIDS. J Gen Intern Med. 2009;24(10):1101-1108.

38. Ammassari A, Trotta MP, Murri R. Correlates and predictors of adherence to highly active antiretroviral therapy: overview of published literature. J Acquir Immune Defic Syndr. 2002;31(3):123-127.

39. Wagner GJ, Goggin K, Remien RH, et al; MACH14 Investigators. A closer look at depression and its relationship to HIV antiretroviral adherence. Ann Behav Med. 2011;42(3):352-360.

40. Reynolds NR, Testa MA, Marc LG, et al; Protocol Teams of ACTG 384, ACTG 731 and A5031s. Factors influencing medication adherence beliefs and self-efficacy in persons naive to antiretroviral therapy: a multicenter, cross-sectional study. AIDS Behav. 2004;8(2):141-150.

41. Mitzel LD, Vanable PA, Brown JL, Bostwick RA, Sweeney SM, Carey MP. Depressive symptoms mediate the effect of HIV-related stigmatization on medication adherence among HIV-infected men who have sex with men. AIDS Behav. 2015;19(8):1454-1459.

42. Gonzalez JS, Batchelder AW, Psaros C, Safren SA. Depression and HIV/AIDS treatment nonadherence: a review and meta-analysis. J Acquir Immune Defic Syndr. 2011;58(2):1-13.

43. Friedman M, Stall R, Silvestre A, et al. Effects of syndemics on HIV viral load and medication adherence in the multicentre AIDS cohort study. AIDS. 2015;29(9):1689-1699.

44. Rudy BJ, Murphy DA, Harris DR, Muenz L, Ellen J; Adolescent Trials Network for HIV/AIDS Interventions. Patient-related risks for nonadherence to antiretroviral therapy among HIV-infected youth in the United States: a study of prevalence and interactions. AIDS Patient Care STDS. 2009;23(3):185-194.

45. Horne R, Chapman SCE, Parham R, Freemantle N, Forbes A, Cooper V. Understanding patients' adherence-related beliefs about medicines prescribed for long-term conditions: a meta-analytic review of the necessity-concerns framework. PLoS One. 2013;8(12):e80633.

46. Saberi P, Neilands TB, Vittinghoff E, Johnson MO, Chesney M, Cohn SE. Barriers to antiretroviral therapy adherence and plasma HIV RNA suppression among AIDS clinical trials group study participants. AIDS Patient Care STDS. 2015;29(3):111-116.

47. Sankar A, Wunderlich T, Neufeld S, Luborsky M. Sero-positive African Americans' beliefs about alcohol and their impact on antiretroviral adherence. AIDS Behav. 2007;11(2):195-203.

48. Kalichman SC, Amaral CM, White D, et al. Prevalence and clinical implications of interactive toxicity beliefs regarding mixing alcohol and antiretroviral therapies among people living with HIV/AIDS. AIDS Patient Care STDS. 2009;23(6):449-454.

49. Kalichman SC, Amaral CM, White D, et al. Alcohol and adherence to antiretroviral medications: interactive toxicity beliefs among people living with HIV. J Assoc Nurses AIDS Care. 2012;23(6):511-520.

50. Kalichman SC, Kalichman MO, Cherry C, et al. Intentional medication nonadherence because of interactive toxicity beliefs among HIV-positive active drug users. J Acquir Immune Defic Syndr. 2015;70(5):503-509.

51. Kalichman SC, Grebler T, Amaral CM, et al. Intentional non-adherence to medications among HIV positive alcohol drinkers: prospective study of interactive toxicity beliefs. J Gen Intern Med. 2013;28(3):399-405.
Patient Preference and Adherence

\section{Publish your work in this journal}

Patient Preference and Adherence is an international, peer-reviewed, open access journal that focuses on the growing importance of patient preference and adherence throughout the therapeutic continuum. Patient satisfaction, acceptability, quality of life, compliance, persistence and their role in developing new therapeutic modalities and compounds to optimize
Dovepress

clinical outcomes for existing disease states are major areas of interest for the journal. This journal has been accepted for indexing on PubMed Central. The manuscript management system is completely online and includes a very quick and fair peer-review system, which is all easy to use. Visit http://www dovepress.com/testimonials.php to read real quotes from published authors. 